\title{
FACILITATED CORONARY ANASTOMOSIS USING A NITINOL U-CLIP DEVICE: BOVINE MODEL
}

Arthur C. Hill, MD

Timothy P. Maroney, MD

Renu Virmani, MD
Objective: The coronary anastomosis is the most difficult part of the coronary bypass procedure, particularly when using a minimally invasive technique. Methods to facilitate coronary anastomosis will make the minimally invasive approach to coronary bypass feasible. We sought preclinical validation and testing of the design and efficacy of a self-closing penetrating clip that can be used to facilitate the creation of graft-to-coronary endto-side anastomosis.

Methods: The nitinol U-Clip device (Coalescent Surgical, Inc, Sunnyvale, Calif) was used in 13 consecutive calves $(63-118 \mathrm{~kg})$. In each animal, the device was (1) used to create an anastomosis of the right internal thoracic artery to a coronary artery with the heart beating and (2) compared to polypropylene suture when used to repair two carotid arteriotomies. Intraoperative, 1-week, 8-week, and 26-week postoperative angiograms and detailed histopathologic examinations were used to evaluate anastomotic patency and healing characteristics.

Results: The nitinol U-Clip device successfully created right internal thoracic artery-coronary artery anastomoses and repaired carotid arteriotomy sites in 13 consecutive calves. The clip was precisely placed by means of the integrated suture and needle in a fashion similar to that used for conventional suture. The clip met design specifications by reliable release and automatic closure, thereby eliminating knot tying and assisted suture management. At the time of harvest, angiography showed widely patent coronary anastomoses (FitzGibbon grade A criteria, $n=13$ ) and carotid arteriotomy repair sites $(n=13)$. Histopathologic evaluation confirmed normal healing with smooth circumferential neointimal resurfacing at the anastomotic and repair sites.

Conclusions: The nitinol U-Clip design and function was validated in the formation of bovine coronary anastomoses on the beating bovine heart with excellent graft patency and healing characteristics. The nitinol U-Clip device tests favorably when compared with conventional sutures in carotid artery repair. (J Thorac Cardiovasc Surg 2001;121:859-70)
$\mathrm{T}$ echnical and engineering advances can potentially make minimally invasive coronary artery bypass grafting $(\mathrm{CABG})$ easier and faster. The coronary anastomosis is the area in which technologic advancement is needed most. New technology that simplifies and facil-

From the University of California, San Francisco, Calif, the Medical College of Virginia, Richmond, Va, and the Armed Forces Institute of Pathology, Washington, DC.

Read at the Eightieth Annual Meeting of The American Association for Thoracic Surgery, Toronto, Ontario, Canada, April 30-May 3, 2000.

12/6/112936

doi: $10.1067 / \mathrm{mtc} .2001 .112936$ itates coronary microvascular anastomosis for minimally invasive surgery has been difficult to develop because of the complexity of the anastomotic process and the variability of mechanical, anatomic, and pathologic constraints while maintaining the surgeon's desire for control of quality and precision.

A new device, the nitinol U-Clip device (Coalescent Surgical, Inc, Sunnyvale, Calif), has been designed to facilitate coronary anastomosis by reducing the complexity and difficulty of the anastomotic process. The device consists of a self-closing nitinol wire releasably attached to a flexible member and needle (Fig 1). The nitinol wire, once detached from the flexible member, 


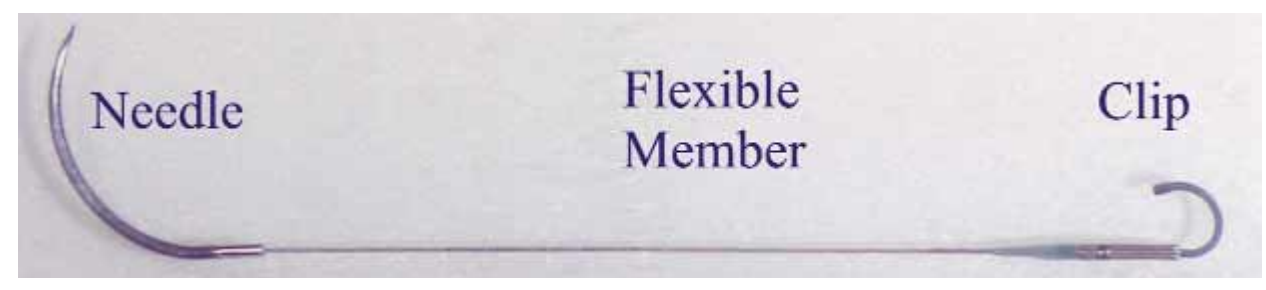

Fig 1. Photograph of the nitinol U-Clip device. The clip comes in "single" and "double arm" configurations (the single arm configuration is shown). It consists of a self-closing clip fabricated from a shape memory alloy nitinol, attached to conventional curved/tapered suture needles via flexible suture-like members. Pressure applied to a release mechanism immediately adjacent to the clip separates the needle/suture components and releases the clip, allowing it to return to its preferred closed-loop configuration.

Table I. Procedure durations and number of clips used

\begin{tabular}{lcccc}
\hline & Animal No. & Occlusion time (min) & Anastomosis time (min) & No. of clips per anastomosis \\
\hline 7 day & 9113 & 19 & 15 & 14 \\
& 9157 & 22 & 15 & 12 \\
8 week & 9185 & 14 & 13 & 13 \\
& 9188 & 17 & 13 & 10 \\
& 9189 & 13 & 12 & 12 \\
& 9161 & 21 & 17 & 13 \\
& 9158 & 23 & 21 & 13 \\
& 9159 & 18 & 10 & 12 \\
26 week & 9160 & 24 & 20 & 13 \\
Average & 9153 & 15 & 13 & 13 \\
Maximum & 9152 & 21 & 20 & 13 \\
Minimum & 59 & 15 & 12 & 13 \\
& 85 & 12 & 11 & 12.5 \\
\end{tabular}

functions to approximate and hold tissue together similar to interrupted suture. The superelastic property of the nitinol wire is used to allow precise delivery and positioning of the device and produce strong and atraumatic tissue approximation. Conventional sutured anastomosis, for optimal performance, requires an assistant for suture management (suture tensioning and positioning) and requires knot tying. The nitinol U-Clip device facilitates microvascular anastomosis by eliminating suture management and knot tying; it is especially useful for endoscopic and robotic methods of CABG. ${ }^{1-4}$

\section{Materials and methods}

Anastomosis device. The nitinol U-Clip device was used for all vascular anastomoses and repairs. The performance of the device was assessed to determine efficacy and ease of use. Performance criteria were set with an expectation of less than a $0.1 \%$ failure rate. Device failure was defined as any or a combination of the following: difficult or nonfunctional detachment of the nitinol wire, inadequate shape change from the open U-shape to the closed loop configuration, gross tissue injury, and need to use alternative or conventional suture.

Experimental protocol. The study was divided into 2 experimental subprotocols: (1) anastomosis of the right internal thoracic artery (RITA) graft to a coronary artery on the beating heart (OPCAB) with the use of the nitinol U-Clip anastomosis device and (2) carotid arteriotomy closure comparing the nitinol U-Clip repair to polypropylene suture repair.

Animals. The experiments were performed after approval of the local ethics committee and in accordance with the "Guide for the Care and Use of Laboratory Animals," as revised by the National Institutes of Health in 1985. ${ }^{5}$ Thirteen consecutive Holstein calves (age 2 to 4 months; weight 63$118 \mathrm{~kg}$ ) were used. All animals received $650 \mathrm{mg}$ of aspirin daily from 3 days before the operation until they were put to death. Postoperative care was delivered in an intensive care unit, and all animals were housed in a barn or pasture until being put to death. 


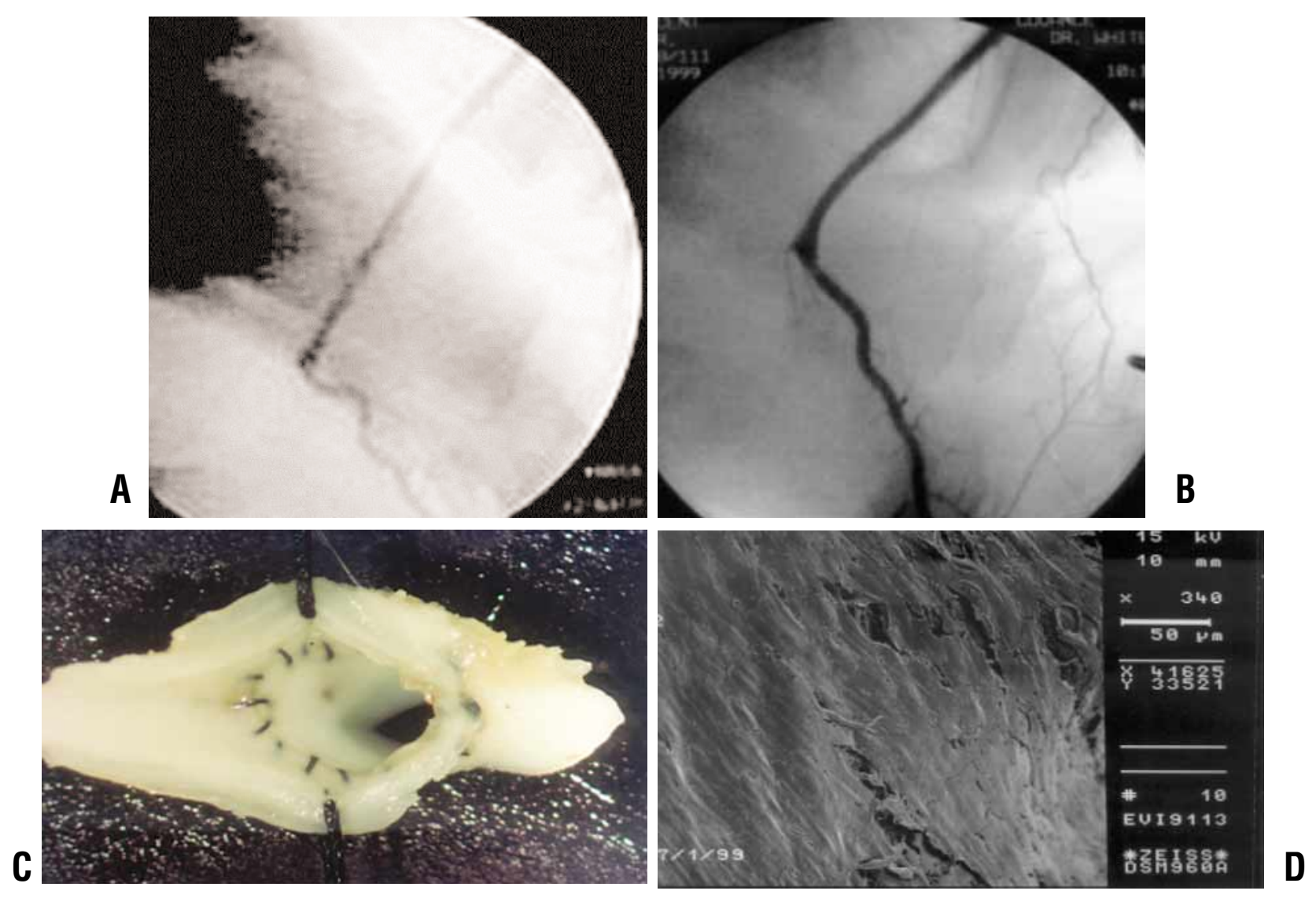

Fig 2. A, Intraoperative angiogram of clipped anastomosis showing wide anastomotic patency and intentional occlusion of the coronary artery proximal to the anastomosis. B, Postoperative angiogram of clipped coronary anastomosis at 7 days. $\mathbf{C}$, Gross view of clipped coronary anastomosis after excision at 7 days. D, Scanning electron microscopic imaging of the interior of the anastomotic line overlying a cup showing smooth neointimal resurfacing and endothelial cells oriented along the direction of blood flow. (All figures are taken from the same animal.)

Coronary anastomosis. The calves underwent general anesthesia and were placed in the right lateral decubitus position. After sterile preparation, a left lateral thoracotomy incision was made in the fifth intercostal space. The RITA was mobilized throughout its intrathoracic length. Intravenous heparin $(10,000 \mathrm{U})$ was administered. RITA flow was measured by means of a Doppler ultrasound 3-mm flow probe (Transonics Systems, Inc, Ithaca, NY) before and after anastomosis. RITA internal diameter, wall thickness, and pedicle length were measured with calipers. A target vessel was selected (left anterior descending, obtuse marginal, or diagonal branch, depending on anatomic presentation and artery size), and its internal diameter was measured. Motion reduction at the anastomotic site was accomplished by means of a stabilizer. Preischemic conditioning was used before coronary artery occlusion. The coronary artery was occluded with flexible tapes (Retract-O-Tape; Quest Medical, Inc, Allen, Tex) during the anastomosis. The anastomoses were performed with nitinol U-Clip devices. All anastomoses were accomplished with a uniform technique intended to optimize precision of clip placement, allow maximal intraluminal visu- alization, and avoid anastomotic narrowing. Clips were placed by grasping the attached curved suture needle with standard needle drivers and sequentially piercing each vessel wall at the desired location in identical fashion as conventional suture. Once the tissue was approximated, the needle and flexible member were pulled through the vessel walls until the vessel walls were seated within the open clip in the desired apposition. Once accurately placed, a needle holder was used to compress a 1-mm long segment of the device at the junction of the flexible member and the nitinol clip (the release mechanism), thereby producing simultaneous detachment of the needle/flexible member from the clip and automatic closure of the clip from a U-shaped configuration to a closed loop configuration. On completion of all anastomoses, the grafted coronary artery was occluded just proximal to the anastomosis with a ligature.

Carotid arteriotomy repair. The left carotid artery was exposed through an incision along the anterior aspect of the sternocleidomastoid muscle. Two carotid arteriotomies, 2.5 $\mathrm{cm}$ each, were placed and separated from each other by $3 \mathrm{~cm}$ of normal arterial tissue. The carotid artery was occluded dur- 

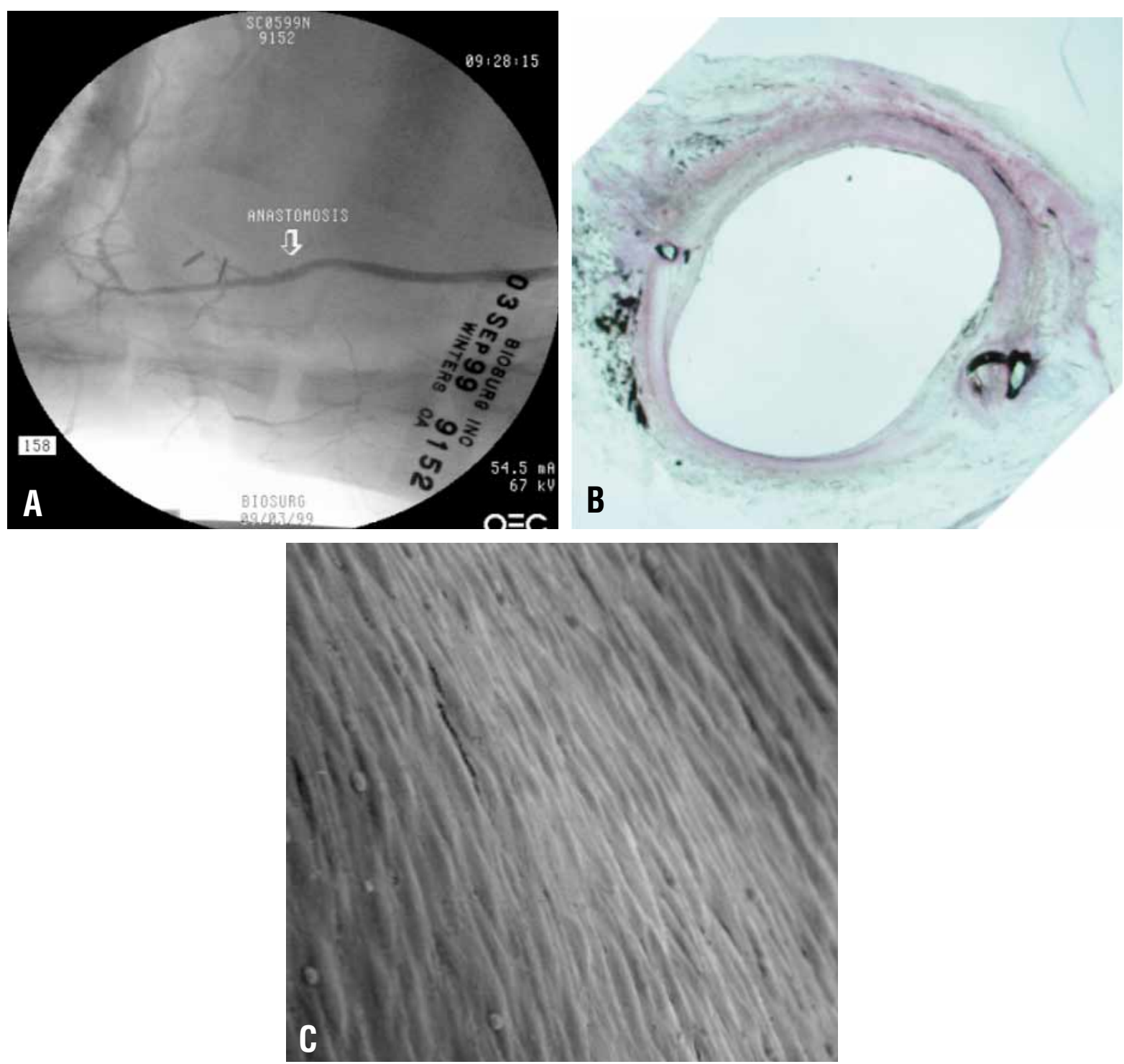

Fig 3. A, Postoperative angiogram of clipped bovine coronary anastomosis (right internal thoracic artery [3 $\mathrm{mm}]$ to second diagonal branch $[1.9 \mathrm{~mm}]$ ), taken at 8 weeks, showing a widely patent anastomosis with no stenosis at the anastomotic site. B, Light micrograph (hematoxylin and eosin stain) of clipped bovine coronary anastomosis at 8 weeks showing smooth neointimal resurfacing, no tissue necrosis, and minimal inflammation. C, Scanning electron microscopic imaging of the inner surface of the clipped coronary anastomotic line with intact endothelial layer.

ing arteriotomy and repair. One carotid arteriotomy was repaired with interrupted nitinol U-Clip devices and the other with continuous 6-0 polypropylene suture.

Angiographic analysis. All coronary anastomoses were studied by angiography immediately after the operation. Subsequent coronary angiographic studies were performed at the following intervals: 7 days $(n=3), 8$ weeks $(n=8)$, and 26 weeks $(n=2)$. Coronary angiographic patency was quantified on the basis of the FitzGibbon criteria ${ }^{6}$ for anastomotic patency. At the same intervals used for performing the coro- nary angiograms, left carotid angiography was also performed on all animals to assess the left carotid arteriotomy repair sites. An experienced radiologist independently evaluated all angiograms at the completion of the study.

Histologic analysis. The calves were put to death after the angiographic studies at the following intervals: 7 days $(n=3)$, 8 weeks $(n=8)$, and 26 weeks $(n=2)$. At sacrifice, the tissue was examined and the heart and carotid arteries were removed. These samples were perfusion-fixed at $100 \mathrm{~mm} \mathrm{Hg}$ pressure with $10 \%$ buffered formalin and transferred to the 
Table II. Angiographic and histologic findings in the coronary artery intraoperatively and before sacrifice related to percent stenosis

\begin{tabular}{|c|c|c|c|c|c|c|}
\hline & \multirow[b]{2}{*}{ Animal No. } & \multicolumn{2}{|c|}{$\begin{array}{c}\text { Intraop at } \\
\text { anastomotic site }\end{array}$} & \multicolumn{2}{|c|}{$\begin{array}{c}\text { Before sacrifice at } \\
\text { anastomotic site }\end{array}$} & \multirow{2}{*}{$\begin{array}{c}\begin{array}{c}\text { Histologic stenosis } \\
\text { at site }\end{array} \\
\text { Percent stenosis }\end{array}$} \\
\hline & & Percent stenosis & FitzGibbon scale & Percent stenosis & FitzGibbon scale & \\
\hline \multirow[t]{3}{*}{ 7-day animals } & 9113 & 0 & A & 0 & A & 0 \\
\hline & 9157 & $70-80$ & B & $30-40$ & A & 50 \\
\hline & 9185 & $60-70$ & B & $<50$ & A & 0 \\
\hline \multirow[t]{8}{*}{ 8-week animals } & 9152 & 0 & A & 0 & A & 0 \\
\hline & 9153 & 0 & A & 0 & A & 0 \\
\hline & 9159 & $<30$ & A & $<10$ & A & 0 \\
\hline & 9160 & $<20$ & A & 0 & A & 10 \\
\hline & 9158 & 0 & B & 0 & A & 0 \\
\hline & 9161 & 40 & A & 0 & A & 0 \\
\hline & 9188 & 0 & $\mathrm{~B}$ & 0 & A & 0 \\
\hline & 9189 & 0 & A & 0 & A & 0 \\
\hline \multirow[t]{2}{*}{ 26-week animals } & 59 & 0 & A & 0 & A & 0 \\
\hline & 85 & 20 & A & 0 & A & NA \\
\hline
\end{tabular}

Armed Forces Institute of Pathology Laboratory in Washington, DC, for preparation and analysis. Samples were split between scanning electron microscopy and light microscopy. Light microscopic samples were injected with barium gelatin before section and histologic examination. Macroscopic photographs were taken of samples designated for scanning electron microscopic analysis. Quantitative measures of tissue healing and inflammation (neointimal thickness, intimal proliferation as percent of intimal thickness, and inflammation rating) were used as isolated observations in the coronary anastomoses and for comparison of polypropylene sutured repair versus nitinol U-Clip repair in the carotid arteriotomy repair model.

\section{Results}

Anastomotic procedure. The average elapsed time from beginning to end of coronary anastomosis was 14.8 minutes (range 10-21 minutes). Total procedure time averaged 187 minutes (range 140-250 minutes), RITA harvest time averaged 34.7 minutes (range 2065 minutes), and coronary occlusion time averaged 18 minutes (range 12-24 minutes). All 13 calves survived until the time of intended sacrifice at 7 days $(n=3), 8$ weeks $(\mathrm{n}=8)$, and 26 weeks $(\mathrm{n}=2)$ (Table I). The average number of clips per anastomosis was 12.5 (range 10-14). Precise placement of clips was facilitated by the integrated needle and flexible wire member connecting the needle and clip. The nitinol U-Clip device met performance criteria to effect strong tissue approximation without tissue injury. The nitinol wire reliably detached from the flexible member and needle unit, and it simultaneously underwent superelastic phase transformation actuating the wire shape change from the open U-shape to the closed loop. All clips were observed to provide consistent and reliable closing force appropriate for creation and maintenance of the desired tissue approximation for a high-quality anastomosis. In 2 of the calves (Nos. 9152 and 9158), a clip not optimally placed was easily removed by means of a removal tool and without tissue injury. There was no significant bleeding at the anastomotic site, and there was no need to use suture as an adjunct to complete the anastomosis.

\section{Angiographic analysis}

Intraoperative findings (coronary only). Examination of intraoperative angiograms confirmed that all 13 animals had patent anastomoses (FitzGibbon grade A, n = 9; and grade $\mathrm{B}, \mathrm{n}=4$ ) (Table II). All 13 RITA-coronary anastomoses were observed by intraoperative angiography to have excellent flow, good distal runoff, and occlusion of the coronary artery proximal to the anastomotic site (Fig 2, A).

Coronary angiographic findings at time of sacrifice. Examination of angiograms taken immediately before sacrifice (Figs 2, B, 3, A, and 4, A) confirmed that all 13 animals had a patent and functioning anastomosis at the following time intervals: 7 days $(\mathrm{n}=3), 8$ weeks ( $\mathrm{n}$ $=8)$, and 26 weeks $(\mathrm{n}=2)$. All anastomoses $(\mathrm{n}=13)$ met FitzGibbon grade A criteria at the end point of the study (Table II). Of the 3 animals put to death at 7 days, 1 had a widely patent anastomosis and 2 continued to show partial narrowing at or around the anastomosis site. Animal 9157 had a 30\% to $40 \%$ narrowing and animal 9185 had only a mild improvement in the $60 \%$ to $70 \%$ narrowing observed in the intraoperative 

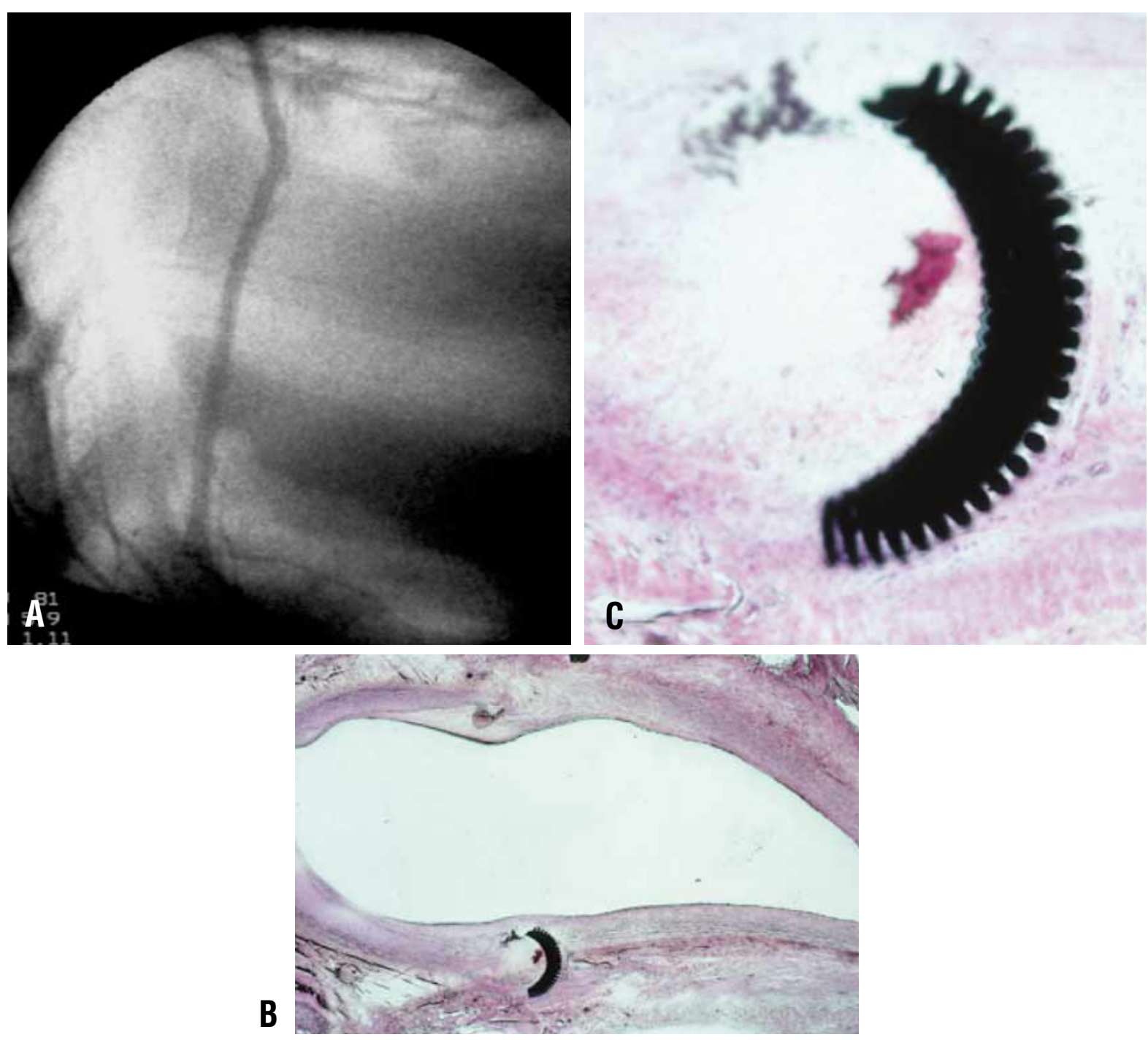

Fig 4. A, Postoperative angiogram of clipped bovine coronary anastomosis taken at 6 months. B, Light micrograph (hematoxylin and eosin stain, magnified $2 \times$ ) of clipped bovine coronary anastomosis at 6 months showing smooth neointimal resurfacing, no tissue necrosis, and minimal inflammation. C, Higher magnification light micrograph (hematoxylin and eosin stain, magnified 10×) of the same clipped bovine coronary anastomosis taken at 6 months (B) showing detail of the clip and surrounding vascular tissue.

angiogram. Just before being put to death, 7 of the 8week cases were found to have widely patent anastomoses with no narrowing or stenosis at the anastomotic site and excellent flow and distal runoff. Animal 9159 had a less than $10 \%$ narrowing of the anastomotic site at 8 weeks. Animal 9158 was observed to have an approximately $1-\mathrm{cm}$ saccular aneurysm seen filling late. This was inferior and to the right of the anastomosis with no visible connection to the anastomosis.

Carotid angiographic findings at time of sacrifice (carotid arteriotomy closures). All 13 carotid arteri- otomies were found to be widely patent, with 1 case of mild narrowing on angiogram at 7 days (animal 9157; Fig 5, A; Table III). There appeared to be no significant difference in angiographic findings between 7 days, 8 weeks, and 6 months. On gross examination of the arteriotomy closure sites, frequent external irregularities were observed at both the clip and suture sites with no effect on the internal vessel diameter. Fundamentally, there was no difference in the quality of the angiographic results between the arteriotomy closures completed with the clips as compared with sutures (Table III). 

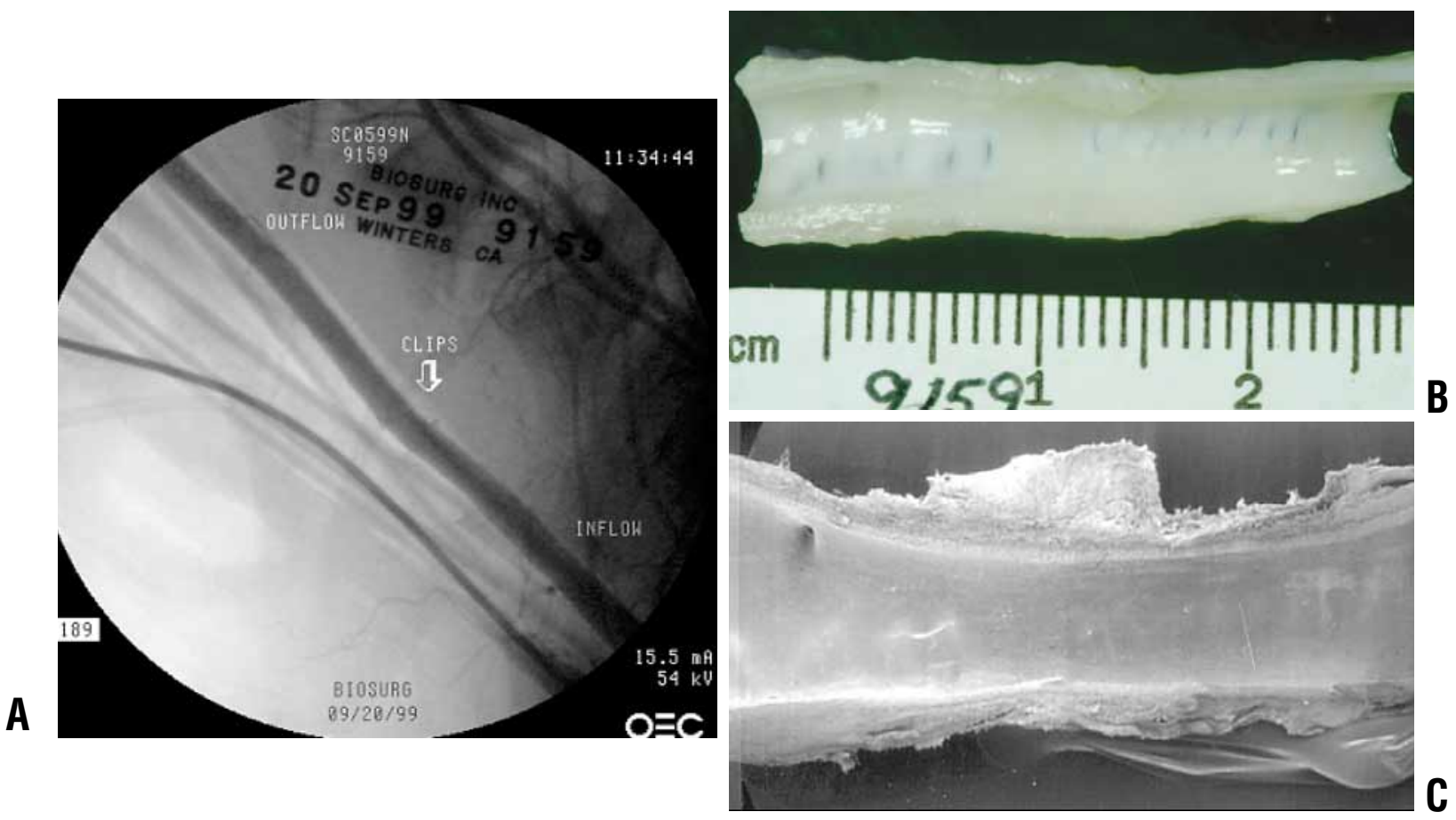

Fig 5. A, Carotid angiogram taken before sacrifice at 8 weeks showing similarity between arteriotomies closed with the nitinol U-Clip device and polypropylene suture. B, Gross view of the left carotid artery showing nitinol U-Clip device (left) versus polypropylene repair (right). C, Scanning electron microscopic view of left carotid artery showing nitinol U-Clip device versus polypropylene repair.

Table III. Carotid angiography of carotid repair sites before sacrifice

\begin{tabular}{lccc}
\hline & & \multicolumn{2}{c}{ Before sacrifice angiography } \\
\cline { 2 - 4 } 7 day & Animal No. & Carotid surface characteristics & Luminal integrity \\
& 9113 & Mild external irregularity & No compromise \\
& 9157 & Mild narrowing & No compromise \\
& 9185 & Mild external irregularity & No compromise \\
& 9152 & No irregularity & No compromise \\
& 9153 & No irregularity & No compromise \\
& 9159 & No irregularity & No compromise \\
& 9160 & Mild external irregularity & No compromise \\
& 9158 & No irregularity & No compromise \\
& 9161 & Mild external irregularity & No compromise \\
& 9188 & No irregularity & No compromise \\
& 9189 & No irregularity & No compromise \\
& 59 & No irregularity & No compromise \\
\hline
\end{tabular}

\section{Histologic analysis}

Coronary anastomotic histopathology. Histopathologic examination of all coronary anastomoses created with the nitinol U-Clip device showed smooth neointimal resurfacing throughout the entire circumference of the inner anastomotic line (Figs 2, C, 2, D, 3, B, 4, B, and
4, C). Endothelial cells covering the clips were oriented in the direction of blood flow (Figs 2, D, and 3,C). There was no significant demarcation between clip and tissue (Table IV). One anastomosis (animal 9157) had a flap of excess graft tissue extending into the lumen of the anastomosis, which produced a histologic anastomotic nar- 
Table IV. Histologic information: Light microscopy—coronary anastomoses and carotid arteriotomy repairs

\begin{tabular}{|c|c|c|c|c|c|c|}
\hline & \multicolumn{6}{|c|}{ Anastomotic site } \\
\hline & 9157 & 9153 & 9158 & 9161 & 59 & 85 \\
\hline Survival & $7 \mathrm{~d}$ & $8 \mathrm{wk}$ & $8 \mathrm{wk}$ & $8 \mathrm{wk}$ & $26 \mathrm{wk}$ & $26 \mathrm{wk}$ \\
\hline $\begin{array}{l}\text { Graft proximal } \\
\text { to anastomosis }\end{array}$ & Normal & Normal & Normal & Normal & Normal & Abnormal \\
\hline Luminal thrombus & Absent & Absent & Absent & Absent & Absent & Present/healed \\
\hline Wall necrosis & Absent & Absent & Absent & Absent & Absent & Present \\
\hline $\begin{array}{l}\text { Intimal proliferation, } \\
\text { narrowing }(\%)\end{array}$ & 0 & 0 & 0 & 0 & 0 & 0 \\
\hline Inflammation & Absent & Absent & Absent & Absent & Absent & Absent \\
\hline \multicolumn{7}{|l|}{$\begin{array}{l}\text { Graft anastomosis/ } \\
\text { arteriotomy repair }\end{array}$} \\
\hline Luminal thrombus & Present & Absent & Absent & Absent & Absent & Present \\
\hline Narrowing (\%) & 75 & 0 & 0 & 0 & 0 & N/A \\
\hline $\begin{array}{l}\text { Intimal proliferation, } \\
\text { narrowing }(\%)\end{array}$ & 8.96 & 12.14 & 13.52 & 13.35 & 12.28 & 0 \\
\hline $\begin{array}{l}\text { Neointimal thick } \\
\qquad(\mu \mathrm{m})\end{array}$ & 200 & 305 & 590 & 550 & 300 & N/A \\
\hline Inflammation & Present & Absent & Absent & Absent & Absent & Present/chronic \\
\hline Inflammation rating & $2+$ & N/A & N/A & N/A & N/A & $2+$ \\
\hline Lymphocytes & 20 & N/A & N/A & N/A & N/A & 50 \\
\hline Macrophages & 80 & N/A & N/A & N/A & N/A & 50 \\
\hline \multicolumn{7}{|l|}{ Reaction at site } \\
\hline Inflammation rating* & $2+$ & $3+$ & $3+$ & $2+$ & $2+$ & $1+$ focal \\
\hline $\begin{array}{l}\text { Coronary tissue } \\
\text { distal to anastomosis }\end{array}$ & Normal & Normal & Normal & Normal & Abnormal & Abnormal \\
\hline Luminal thrombus & Absent & Absent & Absent & Absent & Absent & Absent \\
\hline Wall necrosis & Absent & Absent & Absent & Absent & Absent & Absent \\
\hline $\begin{array}{l}\text { Intimal proliferation, } \\
\text { narrowing }(\%)\end{array}$ & 0 & 0 & 0 & 0 & 21.90 & 34 \\
\hline Inflammation & Absent & Absent & Absent & Absent & Absent & Absent \\
\hline
\end{tabular}

*Inflammation rating: 0 , no inflammatory cells seen; 1 , scattered or occasional inflammatory cells seen; 2 , up to 100 inflammatory cells seen per high-power field; 3 , greater than 100 inflammatory cells per high-power field.

rowing (50\% stenosis) and showed $30 \%$ to $40 \%$ stenosis by angiogram. A second anastomosis of a coronary artery measuring less that $1 \mathrm{~mm}$ in diameter showed histologic narrowing by mural thrombosis with multiple channels suggesting possible recanalization; however, there was no angiographic stenosis at the anastomosis or along the graft. Two additional histopathologic observations (one false aneurysm and one hematoma) were determined by the pathologist to be unrelated to the anastomosis or to the use of the nitinol clip and located at sites of coronary occlusion or stabilization.

Carotid arteriotomy repair histopathology. Histopathologic examination of clipped and polypropylene sutured carotid arteriotomy repair sites showed smooth neointimal resurfacing throughout the length of both arteriotomy repair sites (Figs 5, B, and 5, C). All sites showed smooth endothelial cell covering and similar inflammatory response. No unusual inflammatory reaction and no luminal compromise were observed.
Pathologic findings on the carotid repairs showed similar surface irregularities between clips and sutures with full endothelialization of the endothelial surfaces. No differences could be seen on scanning electron or light microscopy between suture or clip arteriotomy closure (Figs 6, A, 6, B, and 7).

\section{Discussion}

All animals survived the requisite amount of time in apparent good health with no signs of vascular insufficiency or stress. The clip performed exceptionally well intraoperatively with placement and positioning similar to that of suture. Clip deployment and delivery mechanism release were easy and reliable. Intraoperative flow measurements were recorded with the variability typical of this measurement, and intraoperative angiograms showed excellent patency (FitzGibbon grades A and B), flow, and distal runoff with some spasm and edema (associated with stabilization and temporary ligation by 


\begin{tabular}{|c|c|c|c|c|c|c|c|c|c|}
\hline \multicolumn{5}{|c|}{ Arteriotomy site (nitinol clips) } & \multicolumn{5}{|c|}{ Arteriotomy site (suture) } \\
\hline 9157 & 9153 & 9158 & 59 & 85 & 9157 & 9153 & 9158 & 59 & 85 \\
\hline $7 d$ & $8 \mathrm{wk}$ & $8 \mathrm{wk}$ & $26 \mathrm{wk}$ & $26 \mathrm{wk}$ & $7 d$ & $8 \mathrm{wk}$ & 8 wk & $26 \mathrm{wk}$ & $26 \mathrm{wk}$ \\
\hline
\end{tabular}

\begin{tabular}{|c|c|c|c|c|c|c|c|c|c|}
\hline Absent & Absent & Absent & N/A & Absent & Absent & Absent & Absent & N/A & Absent \\
\hline 0 & 0 & 0 & N/A & 0 & 0 & 0 & 0 & N/A & 0 \\
\hline 2.84 & 4.44 & 3.62 & N/A & 12.46 & 2.29 & 4.18 & 13.65 & N/A & 12.42 \\
\hline 200 & 490 & 350 & N/A & 690 & 240 & 300 & 600 & N/A & 580 \\
\hline $2+$ & $3+$ & $3+$ & N/A & 0 & $2+$ & $3+$ & $3+$ & N/A & 0 \\
\hline
\end{tabular}

vessel loops during the procedure) in 9 of 13 cases. Elimination of distal vessel loops could have reduced this vascular trauma.

Overall angiographic patency results before sacrifice using the scale developed by FitzGibbon (grades A, B, and $\mathrm{O}$ ) compared very favorably with results documented in the literature, including CABG and OPCAB/MID$\mathrm{CAB}$ clinical studies that have included postoperative angiography published by Tyras, ${ }^{7}$ Berger, ${ }^{8}$ Calafiore, ${ }^{9}$ Gill, ${ }^{10}$ Mack, ${ }^{11}$ and their associates.

In animal 9185, the angiographic interpretation of the coronary anastomosis was $50 \%$ stenosis after 7 days; the histologic interpretation of the same anastomosis was no stenosis at 7 days. This discrepancy may have resulted from right internal thoracic artery-coronary flow characteristics or to limited viewing angles obtained in the use of the fluoroscopic device in the laboratory.

The principal objective of this study was to provide data to the US Food and Drug Administration regarding the relative safety of the nitinol U-Clip device before an investigational device exemption (IDE) application for clinical study; consequently, it was not specifically designed to study the difference between interrupted and continuous suture technique. However, one of the most important potential benefits of a clip that could be used to accomplish precise coronary microanastomosis is the enabling of rapid interrupted suture technique.

The question of continuous versus interrupted suture technique as applied to coronary anastomoses has received little objective study and has recently been eclipsed by the debate over the relative merits of stopped versus beating-heart methods. The relative paucity of comparative studies showing a clear advantage of an interrupted technique coupled with the historic advantages of continuous technique in terms of speed and ease of use have served to advance what is possibly an inferior practice. Problems with continuous suture technique include reduction in expansion ability in growing vessels, reduced flexibility, anastomotic 

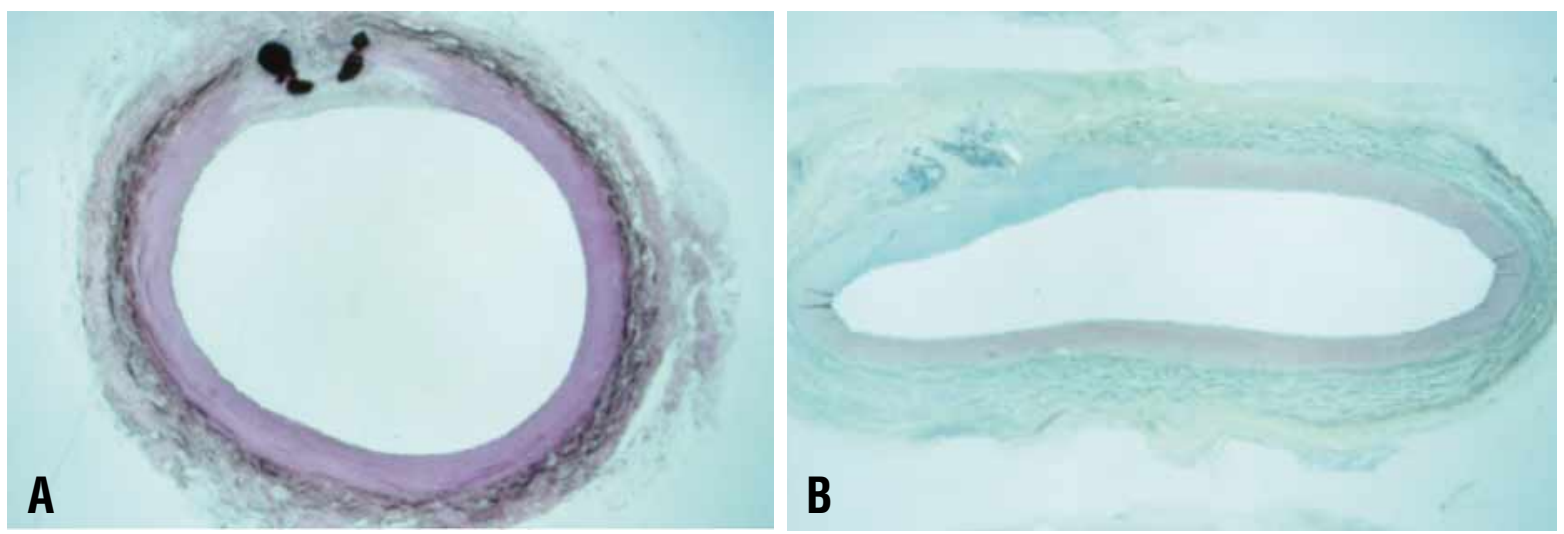

Fig 6. A, Nitinol U-Clip repair of carotid arteriotomy at 6 months; cross-section light microscopy ( $2 \times)$ with hematoxylin and eosin staining. B, Polypropylene repair of carotid arteriotomy at 6 months; cross-section light microscopy $(2 \times)$ with hematoxylin and eosin staining.
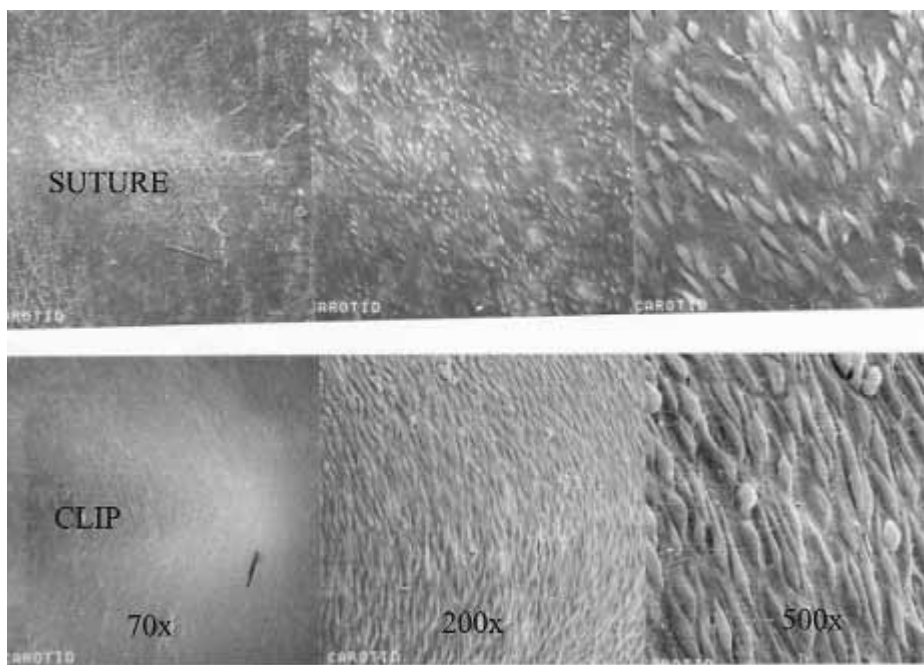

Fig 7. Comparison of scanning electron microscopic imaging of polypropylene suture (top) versus nitinol U-Clip (bottom) repair of carotid arteriotomies at $70 \times$ (left), $200 \times$ (center), and $500 \times($ right) magnification.

narrowing, and irregularity. This technology can eliminate the disadvantages of the current sutured anastomotic technique, that is, knot tying and suture management, and may well presage a shift toward a potentially superior interrupted technique.

\section{Conclusions}

The operative and perioperative safety and effectiveness of the nitinol U-Clip device when used for vascular tissue approximation was confirmed. All arteriotomy and coronary anastomoses were completed successfully with no intraoperative problems or adverse events. The long-term effectiveness of the nitinol UClip device for vascular anastomosis and arteriotomy repair was demonstrated as well. All animals survived the requisite amount of time in good health. Vessel patency was excellent, with all vessels found to be functionally patent with excellent runoff when harvested. The moderate narrowing seen in 2 of the anastomoses was a function of vessel size differences and operative and surgical technique that was entirely unrelated to the use of the nitinol U-Clip devices. Biocompatibility of the nitinol U-Clip device was validated. The healing and pathologic responses were excellent, with all clips fully covered with an endothelial layer with minimal inflammatory response and an absence of necrosis. The results of carotid repair were also excellent and were equivalent to the control 
carotid repair completed with suture. In conclusion, the study successfully showed that the nitinol U-Clip device performs as designed and that it can be used safely and effectively for the creation of anastomoses in blood vessels and for vascular arteriotomy repair. This self-closing clip technology, with corresponding elimination of requirements for knot tying and management of suture, should have a positive impact on both minimally invasive technique (including endoscopic and robotic surgery) and beating-heart methods and may presage a shift to interrupted technique with a corresponding improvement in anastomotic quality.

Received for publication May 4, 2000; revisions requested Aug 15, 2000; revisions received Nov 3, 2000; accepted for publication Nov 9, 2000.

Address for reprints: Arthur C. Hill, MD, Department of Surgery, University of California at San Francisco, San Francisco General Hospital, 1001 Potrero Ave, Box 0807, San Francisco, CA 94143-0807.

\section{REFERENCES}

1. Boehm DH, Reichenspurner H, Gulbins H, Detter C, Meiser B, Brenner P, et al. Early experience with robotic technology for coronary artery surgery. Ann Thorac Surg 1999;68:1542-6.

2. Mack MJ, Acuff TE, Casimir-Ahn H, Lonn UJ, Jamsen EWL. Video-assisted coronary bypass on the beating heart. Ann Thorac Surg 1997;63:S100-3.

3. Shennib H, Bastawisy A, McLoughlin J, Moll F. Robotic computer assisted telemanipulation enhances coronary artery bypass. J Thorac Cardiovasc Surg 1999;117:310-3.

4. Loulmet D, Carpentier A, d'Attelis N, Berrebi A, Cardon C, Ponzio O, et al. Endoscopic coronary artery bypass grafting with the aid of robotic assisted instruments. J Thorac Cardiovasc Surg 1999;118:4-10.

5. National Institutes of Health. Guide for the care and use of laboratory animals. Bethesda (MD): National Institutes of Health; 1985. Publication No. 86-23.

6. FitzGibbon GM, Kafka HP, Leach AJ, Keon WJ, Hooper GD, Burton JR. Coronary bypass graft fate and patient outcome: angiographic follow-Up of 5,065 grafts related to survival and reoperation in 1,388 patients during 25 years $\mathrm{J}$ Am Coll Cardiol 1996;28:616-26.

7. Tyras DH, Barner HB, Kaiser GC, Codd JE, Pennington DG, Willman VL. Bypass graft to the left anterior descending coronary artery: saphenous vein versus internal mammary artery. $\mathrm{J}$ Thorac Cardiovasc Surg 1980;80:327-33.

8. Berger PB, Alderman EL, Nadel A, Schaff HV. Frequency of early occlusion and stenosis in a left internal mammary artery to left anterior descending artery bypass graft after surgery through a median sternotomy on conventional bypass: benchmark for minimally invasive direct coronary artery bypass. Circulation 1999;100:2353-8.

9. Calafiore AM, Teodori G, Di Giammarco G, Vitolla G, Contini M. Minimally invasive coronary artery surgery: the LAST operation. Semin Thorac Cardiovasc Surg 1997;9:305-11.

10. Gill IS, FitzGibbon GM, Higginson LA, Valji A, Keon WJ.
Minimally invasive coronary artery bypass: a series with early qualitative angiographic follow-up. Ann Thorac Surg 1997;64: 710-4.

11. Mack MJ, Magovern JA, Acuff TA, Landreneau RJ, Tennison DM, Tinnerman EJ, et al. Results of graft patency by immediate angiography in minimally invasive coronary artery surgery. Ann Thorac Surg 1999;68:383-90.

\section{Discussion}

Dr Hani Shennib (Montreal, Quebec, Canada). Dr Hill, I have 3 questions for you. There are some theoretical advantages of doing interrupted sutures rather than running sutures, and there are some "hassle factors" associated with tying and so on. Clearly, this technology potentially would eliminate the hassle factors of suture tying and handling. Do you perceive a learning curve, as this is a new instrument and method to which surgeons must adapt? Do you see a learning curve as an impediment to use of this device?

Second, you propose moving from very simple sutures, which are inexpensive, to something that would entail the use of nitinol, which is more expensive. Would that cost be easily acceptable within a cardiac surgery practice?

Third, the ultimate purpose is to do a least invasive procedure. How do you foresee that a technology like this would be incorporated in a delivery system that lends itself to lesser access?

Dr Hill. Most surgeons already possess the skill required to place this device. The placement and delivery of the device is very similar to suturing, both continuous and interrupted. There is somewhat of a learning curve in determining the site of placement of the needle holders for the release mechanism. It is very simple once the exact site is learned, and it eliminates knot tying, very difficult maneuvers in endoscopic and robotic surgery. I think the learning curve for one approaching robotics and endoscopy will be decreased.

With respect to cost, this will be more expensive than standard polypropylene suture. But again, with the push toward minimally invasive procedures, the shorter hospital stay offsets costs, and I think the costs can be offset with the increased cost of this particular device. It is estimated that this device should cost about $\$ 150$ per anastomosis.

Dr Paul F. Grundeman (Utrecht, The Netherlands). I have to congratulate you, Dr Hill, for this beautiful device. I think it has great potential for endoscopic CABG.

I have 2 questions related to flow in your animal model. Mean flow was about $81 \mathrm{~mL} / \mathrm{min}$. How do you foresee that this anastomotic device will hold in a flow of about 30 $\mathrm{mL} / \mathrm{min}$ in the human left internal thoracic artery-left anterior descending bypass?

Second, do you use anticoagulant therapy during the operation, and is that continued in the recovery phase?

Dr Hill. I do not think that the decreased flow is going to produce a greater amount of thrombosis than a sutured anastomosis would. The end result should be no different from that obtained with an interrupted suture anastomosis, and I do not think the flow characteristics will be any different. 
We used heparin because we occluded the coronary artery during the operation and because the hearts were beating. There was no occlusion or stenosis proximal to this site because these were healthy young calves. We continued the calves on daily aspirin after the operation, but they were not given anticoagulants per se.

Dr Antonio M. Calafiore (Chieti, Italy). I have just a technical question. What is the minimal size of the coronary artery for which this technique can be used? Can this technique be used with the bigger sutures, like 5-0, 4-0, and 2-0, for valve prostheses?

Dr Hill. The minimal size coronary artery I think is more related to the graft size than it is to device size. This device can accommodate 7-0 or 8- 0 suture size. The size of the anastomosis is going to be more closely related to the size of the thoracic artery graft and avoiding mismatch with respect to small coronary sizes and large thoracic artery sizes. I do not think that this device will limit the surgeon's ability to use the smaller sizes that are currently in use. Normally surgeons do not go lower than $1 \mathrm{~mm}$ for coronary anastomoses. I have grafted smaller than 1-mm arteries using this device. We performed a previous study in dogs, which we presented at Utrecht, and many of those coronary arteries were less than $1 \mathrm{~mm}$.

Access to The Journal of Thoracic and Cardiovascular Surgery Online is reserved for print subscribers!

Full-text access to The Journal of Thoracic and Cardiovascular Surgery Online is available for all print subscribers. To activate your individual online subscription, please visit The Journal of Thoracic and Cardiovascular Surgery Online, point your browser to http://www.mosby.com/jtcvs, follow the prompts to activate your online access, and follow the instructions. To activate your account, you will need your subscriber account number, which you can find on your mailing label (note: the number of digits in your subscriber account number varies from 6 to 10). See the example below in which the subscriber account number has been circled:

\section{Sample mailing label}

\begin{tabular}{l|l}
\cline { 2 - 2 } $\begin{array}{l}\text { This is your subscription } \\
\text { account number }\end{array}$ & $\begin{array}{l}* * * * * * * * * * * * * * * * * * * * * * * * * * 3-D I G I T \\
\text { SJ P1 }\end{array}$ \\
FEB00 J027 C: 1 1234567-89 U 05/00 Q: 1 \\
J. H. DOE, MD \\
531 MAIN ST \\
CENTER CITY, NY 10001-001
\end{tabular}

Personal subscriptions to The Journal of Thoracic and Cardiovascular Surgery Online are for individual use only and may not be transferred. Use of The Journal of Thoracic and Cardiovascular Surgery Online is subject to agreement to the terms and conditions as indicated online. 